\title{
Identification of knee osteoarthritis disability phenotypes regarding activity limitation: a cluster analysis
}

\author{
Mantana Vongsirinavarat ${ }^{1 *}$, Patcharin Nilmart ${ }^{2}$, Sirikarn Somprasong ${ }^{1}$ and Benjawan Apinonkul ${ }^{1}$
}

\begin{abstract}
Background: Studies have reported the subtypes of individuals with knee osteoarthritis $(\mathrm{OA})$ attempting to cluster this heterogonous condition. Activity limitations are commonly used to set goals in knee OA management and better identify subgroups based on level of disability in this patient population. Therefore, the objective of this study was to identify those activity limitations which could classify the disability phenotypes of knee OA. The phenotypes were also validated by comparing impairments and participation restrictions.

Methods: Participants comprised individuals with symptomatic knee OA. They were interviewed and undertook physical examination according to a standard evaluation forms based on the International Classification of Functioning, Disability and Health (ICF) model. Cluster analysis was used to determine those activity limitations which could best classify the phenotypes of knee OA. To validate the clustered variables, comparisons and regression analysis were performed for the impairments consisting of pain intensity, passive range of motion and muscle strength, and the participation restrictions included the difficulty level of acquiring goods and services and community life.
\end{abstract}

Results: In all, 250 participants with symptomatic knee OA were enrolled in the study. Three activity limitations identified from data distribution and literature were used as the cluster variables, included the difficulty level of maintaining a standing position, timed stair climbing and 40-m self-paced walk test. The analysis showed four phenotypes of individuals with knee OA according to the levels of disability from no to severe level of disability. All parameters of impairment and participation restrictions significantly differed among phenotypes. Subgroups with greater disability experienced worse pain intensity, limited range of motion (ROM), muscle power and participation restriction levels. The variance accounted for of the subgroups were also greater than overall participants.

Conclusion: The results of this study emphasized the heterogeneous natures of knee OA. Three activity limitations identified could classify the individuals with symptomatic knee OA to homogeneous subgroups from no to severe level of disability. The management plan, based on these homogeneous subgroups of knee OA, could be designated by considering the levels of impairments and participation restrictions.

Keywords: Activities of daily living, Chronic limitation of activity, ICF, Knee, Osteoarthritis, Cluster analysis

\footnotetext{
*Correspondence: mantana.von@mahidol.edu

${ }^{1}$ Faculty of Physical Therapy, Mahidol University, Putthamonthon, Nakhon Pathom 73170, Thailand

Full list of author information is available at the end of the article
}

(c) The Author(s). 2020 Open Access This article is licensed under a Creative Commons Attribution 4.0 International License, which permits use, sharing, adaptation, distribution and reproduction in any medium or format, as long as you give appropriate credit to the original author(s) and the source, provide a link to the Creative Commons licence, and indicate if changes were made. The images or other third party material in this article are included in the article's Creative Commons licence, unless indicated otherwise in a credit line to the material. If material is not included in the article's Creative Commons licence and your intended use is not permitted by statutory regulation or exceeds the permitted use, you will need to obtain permission directly from the copyright holder. To view a copy of this licence, visit http://creativecommons.org/licenses/by/4.0/ The Creative Commons Public Domain Dedication waiver (http://creativecommons.org/publicdomain/zero/1.0/) applies to the data made available in this article, unless otherwise stated in a credit line to the data. 


\section{Background}

Knee osteoarthritis $(\mathrm{OA})$ is a condition with great heterogeneity by its nature. Despite similar structural involvements among people with knee OA, different outcomes of management were observed [1-3]. Classifying this population in homogeneous subgroups might lead to more direct and specific treatments [4]. Related studies have attempted to identify the common phenotypes of knee OA using various methods such as cluster analysis [5], latent class analysis [6], and predefined [7] methods. Considering the definition of phenotype as "the observable properties of an organism that are produced by the interaction of the genotype and the environment" [8], studies had attempted to identify the phenotypes of individuals with knee OA. Impairment physiognomies commonly used as phenotypic variables in research studies involve clinical findings such as pain sensitivity $[9,10]$, knee alignment [7], and gait parameters [11].

Considering the International Classification of Functioning, Disability and Health (ICF) framework, not only impairment but activity limitation and participation restriction were also affected by the pathology of knee OA $[12,13]$. However, participation restriction is usually individualized and depends largely on personal as well as environmental factors. Therefore, functional disability or activity limitation is more commonly used to guide goal setting in knee OA management in rehabilitation. Related studies regarding physical therapy interventions usually evaluated the physical functions of these patients [14-17].

Using activity limitation to identify the phenotypes among patients with knee OA would lead to more specific levels of disability related to the physical therapy treatment goals. Few studies have identified knee OA phenotypes based on variables of activity limitation $[18,19]$. Two studies used the Western Ontario and McMaster Universities Osteoarthritis Index (WOMAC) function subscale as the phenotypic variables $[18,19]$. They reported that adults experiencing risk of knee OA and those with symptomatic knee OA demonstrated a variety of functional decline measured by the WOMAC function subscale. However, the phenotypes based on the sum score of 17 functional activities in WOMAC might not be accurately linked to the physical therapy management $[20$, 21]. The further analysis of the specific items of activities with greater difficulty would be needed.

Identifying specific activities impacted by knee OA should be more useful to guide management and prognosis. However, many activities are associated with knee OA symptoms. Stair climbing, rising from a chair and walking were reportedly the most common functional limitations among individuals with knee OA [22]. Moreover, the practice guidelines of knee OA suggest evaluating the functional capacity of walking, stair climbing, sit- to-stand, and balance ability [23]. Therefore, this study aimed to verify these activity limitations as reported in literature which could specifically classify the phenotypes of individuals with knee OA. The impairments and participation restrictions among phenotypes were also compared to validate the subgroup classification. We hypothesized that specific activity limitations would be identified and these activities could also classify individuals with symptomatic knee OA in homogeneous subgroups regarding level of disability. Moreover, the severity of impairments and participation restrictions would differ among phenotypes and these variables would be able to explain more variances when subgrouping of participants was considered.

\section{Methods \\ Participants}

The participants were enlisted from communities in the areas of services of ten physical therapy primary care settings in Thailand. They comprised individuals with symptomatic knee OA according to the American College of Rheumatology clinical criteria for knee OA [24]. The criteria included joint pain, and having three of the following criteria: 1) crepitus on active joint motion, 2) morning stiffness less than $30 \mathrm{~min}, 3$ ) age more than 50 years, 4) bony enlargement of the knee, 5) bony tenderness of the knee and 6) no palpable warmth [25]. The exclusion criteria comprised participants having inflammatory knee conditions, history of systemic diseases, lower extremity fracture or arthroplasty, previous intraarticular injection within 6 months, cognitive impairment, or impaired movements associated with other conditions. Fig 1 presents the participants' recruitment process. All participants provided written informed consent before collecting data.

\section{Knee $\mathrm{OA}$ assessments}

An extensive assessment list for knee OA based on the ICF was used in this survey [26]. This list was developed using Delphi method consensus by ten physical therapy experts. Assessment tools comprised 16 categories of impairment (body function/body structure), and 33 categories of activity/participation limitation domains considered relevant to individuals with knee OA [26].

The impairment outcomes consisted of the worst pain during $48 \mathrm{~h}$, muscle power of knee flexors and extensors, passive range of motion (PROM) of knee flexion and extension. The worst pain during $48 \mathrm{~h}$ was measured by numerical rating scale. Goniometry was used to measure PROM of knee flexion and extension in the supine lying position. Muscle power was determined according to standard manual muscle test on a 0 to 5 scale [27]. Hip, knee and ankle muscles were tested in supine, prone, sitting and standing positions. 


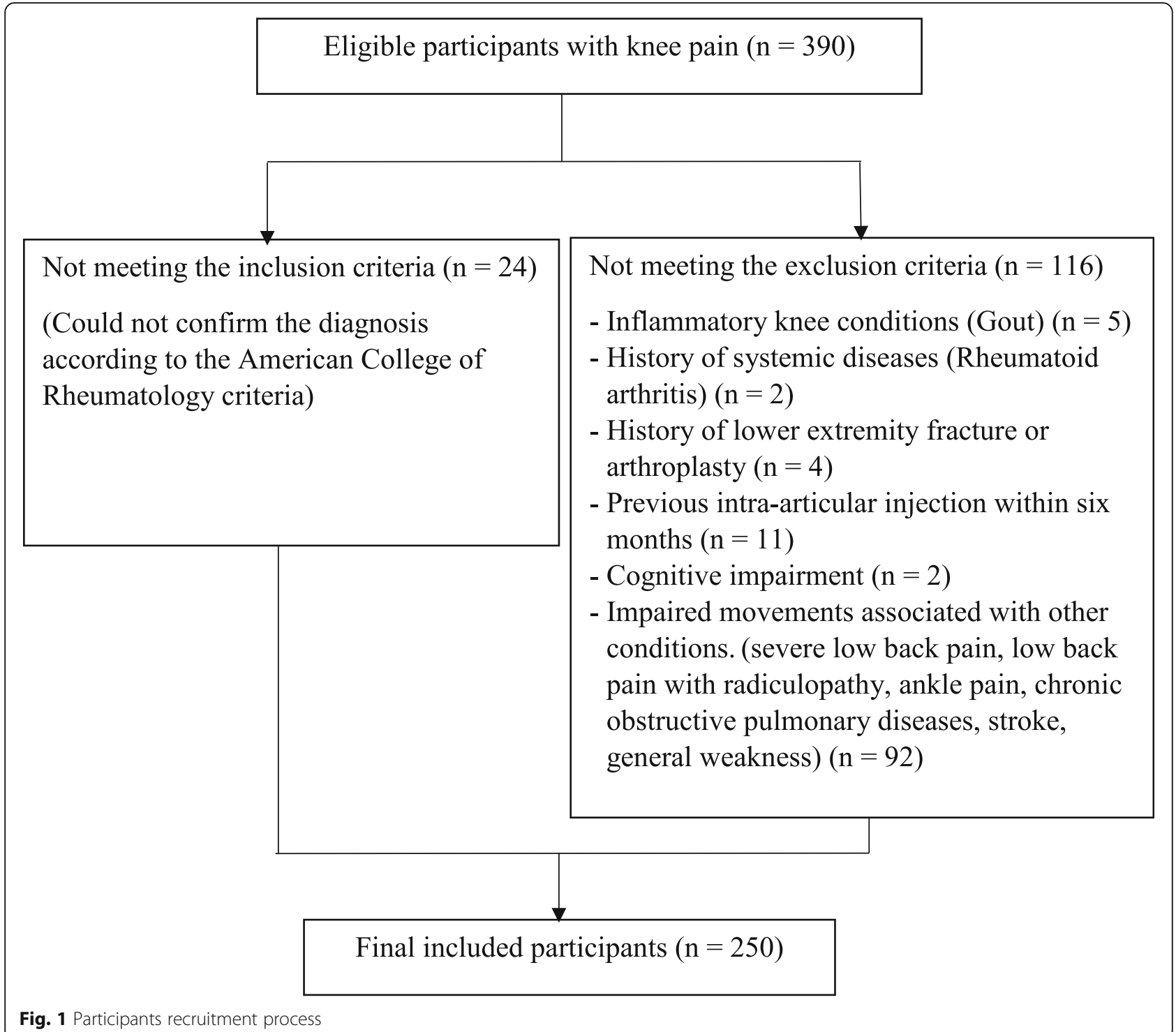

Twenty-three activities from the comprehensive ICF core set for osteoarthritis were assessed including changing basic body position of lying down, changing and maintaining squatting, kneeling, sitting, standing, cross sitting, and side sitting positions, four walking patterns (short and long distance, around obstacles, and on different surfaces), stair climbing, toileting, taking off footwear, putting on and taking of pants, cleaning living area and remunerative employment. All these activities were subjectively examined by asking the participants to indicate the degree of difficulty of the activities during the past week. The rating of zero to four according to ICF qualifier guideline were used as 0 "no difficulty" (0-4\%), 1 "mild difficulty" (5-24\%), 2 "moderate difficulty" (25-49\%), 3 "severe difficulty" (50-95\%), and 4 "complete difficulty" (96-100\%) [12]. The code of 9 as "not applicable" was also available. In addition, two common activity performance tests were also examined to quantify the activity abilities. The walking ability was assessed using timed 40-m self-paced walking and the stair climbing test which timing 5 steps ascending and descending the stair was also used [26].

Ten items of participation restriction, based on the ICF comprehensive core set for OA, were evaluated consisting of using private motorized transportation, using public motorized transportation, driving human-powered transportation, driving motorized vehicle, acquiring goods and services, assisting others in movement, community life, sports, hobbies, and socializing. The ICF qualifier procedure was also used to identify the level of difficulty to perform the participation items [12].

\section{Data analysis}

Descriptive statistics were used to outline the personal characteristics of the participants including age, body 
mass index (BMI) and duration of knee pain. Three cluster variables were identified based on the results of the survey of 23 activities. The selected variables must have proper distributions of difficulty levels among 250 participants. These variables also had to be confirmed by the evidence from literature as the apparently important activity limitations among patients with knee OA.

Two-step cluster analysis was used to classify the phenotypes of knee OA due to the mixed types of cluster variables including both categorical and numeric variables. Optimal number of clusters, log-likelihood distance measure and Schwarz's Bayesian Criterion were used [28].

To validate the phenotypes, the impairment and participation variables were compared. The Kruskal-Wallis test was used to compare pain intensity, knee flexion and extension PROM, muscle power of knee flexors and extensors, the level of difficulty of acquiring goods and services and community life among phenotypes. The statistical significance level was set at 0.05 . The regression analysis was also performed to confirm the variance accounted for of impairment and participation variables for overall and subgroups of participants in each knee OA phenotype.

\section{Results}

In all, 250 participants with symptomatic knee osteoarthritis (OA) were enrolled in this study. Age, BMI, duration of knee pain and proportion of males and females of overall participants and the subgroups from cluster analysis are presented in Table 1 . The BMI were significantly different among subgroups.

Fig. 2 presents the distributions of the responses of 23 activities limitation assessed. Three activities chosen based on literature to possibly be the cluster variables including maintaining standing position, walking long distance and stair climbing met the criteria of 100\% responses and had appropriate distributions of difficulties among 250 participants. Therefore, they were taken into the cluster analysis to further determine the phenotypes of individuals with knee OA. The results of performance tests of timed self-paced walking and stair climbing test were used for the analysis.

\section{Cluster variables and phenotypes of knee OA}

The results of cluster analysis showed that three chosen variables were appropriate for grouping the individuals with knee OA into phenotypes. All 250 cases were entered in the analysis. As presented in Table 2, the results showed four phenotypes with good cluster quality (average silhouette $=0.5$ ). The most important predictors for the cluster membership were maintaining a standing position (1.0) followed by stair climbing time (0.05). The least important was walking time (0.04). The results showed four phenotypes associated with the degree of activity limitation consisting of no (31.6\%), mild (26.8\%), moderate (30.4\%), and severe disability (11.2\%).

After the subgroups were identified, the impairment variables consisting of pain intensity, PROM of knee flexion and extension and strength of knee flexor and extensor muscles were compared among phenotypes. The results are presented in Table 3 as all variables significantly differed among homogeneous subgroups of knee OA $(p<0.05)$. Two out of 10 variables of participation restriction domain which rated by more than $80 \%$ of participants were also used for the verification by comparisons among phenotypes. Both acquiring goods and services and community life demonstrated a significant difference among phenotypes.

Table 4 presents the variance accounted-for statistic models of impairment and participation variables for the activity limitations used as cluster variables among all participants and each cluster. There were marked that the subgroups had greater variance accounted for all three activity limitations compared with the overall participants.

\section{Discussion}

This study aimed to identify the activity limitations appropriate to identify homogeneous subgroups of knee OA. The impairment and participation restriction were then compared among the established subgroups. The results were congregant with our hypotheses. Three variables including difficulty levels of maintaining a standing position, walking time, and stair climbing time represented distinct phenotypes. Four phenotypes were identified with differing levels of disability in knee OA. The impairments and participation restriction levels

Table 1 Demographic data of participants and the subgroups

\begin{tabular}{lllllll}
\hline & All participants $(N=250)$ & $\begin{array}{l}1 \text { (No disability) } \\
(N=79)\end{array}$ & $\begin{array}{l}2 \text { (mild disability) } \\
(N=67)\end{array}$ & $\begin{array}{l}3 \text { (moderate disability) } \\
(N=76)\end{array}$ & $\begin{array}{l}4 \text { (severe disability) } \\
(N=28)\end{array}$ & $\begin{array}{l}P \text { - values } \\
\text { Age (years) }\end{array}$ \\
\hline BMI $\left(\mathrm{kg} / \mathrm{m}^{2}\right)$ & $65.44(8.70)$ & $66.7(7.97)$ & $66.49(9.85)$ & $64.55(8.35)$ & $62.8(6.76)$ & 0.112 \\
Duration of knee pain (years) & $5.02(3.78)$ & $25.13(3.61)$ & $25.30(4.48)$ & $27.37(4.95)$ & $27.07(3.53)$ & $0.003^{\mathrm{a}}$ \\
Gender (female/male) & $216 / 34$ & $5.56(4.24)$ & $5.27(3.72)$ & $4.24(3.14)$ & $4.54(3.18)$ & 0.129 \\
\hline
\end{tabular}

Note: Age, BMI and duration of pain were compared among subgroups using one-way ANOVA. Gender proportion was compared using Chi-square

${ }^{a}$ different among subgroups at $p<.05$. Post-Hoc analysis showed differences between group 1 \& 3 , group 2 \& 3 , and group 2 \& 4 


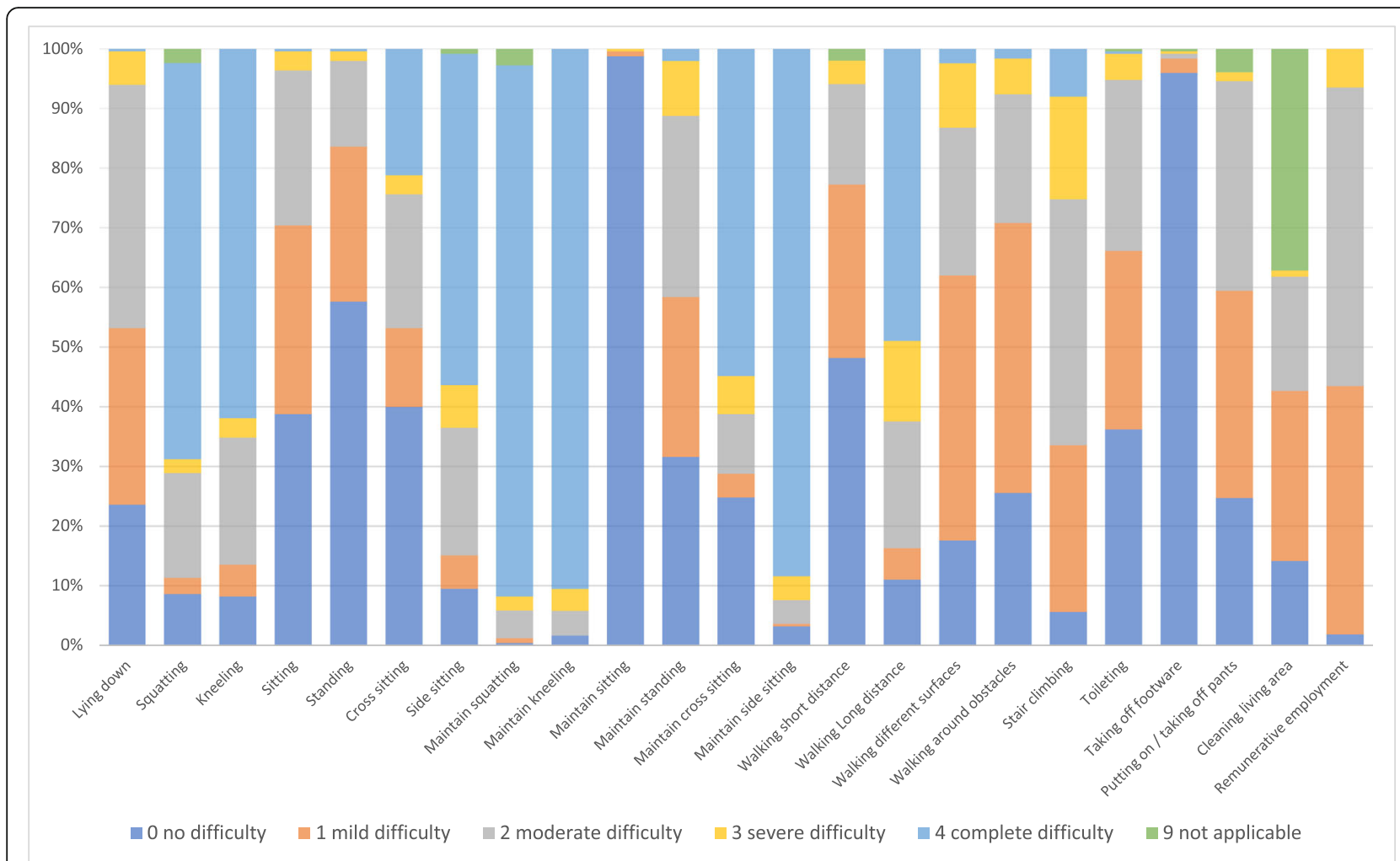

Note: Three activity limitations chosen as the cluster variables are "Maintain standing", "Walking long distance" and "Stair climbing".

Fig. 2 The distributions of the responses of 23 activity limitations assessed

significantly differed among individuals in each phenotype. Greater variance was accounted for when using the subgroups according to the phenotype compared with the overall group. This implied that the subgroup could more precisely identify people not only activity but also their impairments and participation levels. The related literature also confirmed that among patients with knee $\mathrm{OA}$, these three activities were the common ones being assessed and used as functional goals in physical therapy clinics $[13,22,29]$. Therefore, the three activity limitations identified in this study had the power to classify subgroups of people with knee OA.

The activity limitation variables had been used to classify individuals with knee $\mathrm{OA}$ in homogeneous subgroups $[18,19]$. However, the number of phenotypes varied among studies. In this study, activity limitation variables could cluster the patients with knee OA in four phenotypes with the disability levels of no, mild, moderate and severe. A related study conducting 5-year follow-up among people with early symptomatic knee OA identified three phenotypes of knee OA consisting of good, moderate, and poor outcome subgroups [18]. The different characteristics regarding activity limitation decline over time among subgroups was reported. The authors suggested that their homogenous identification of individuals with knee OA could be used to develop specific interventions [18]. Another 7-year follow-up study proposed five phenotypes of people with knee OA differentiated by functional decline. The subgroups comprised high functioning, minimal limitation, late

Table 2 Phenotypes according to the clustered activity limitations

\begin{tabular}{lllll}
\hline & Cluster & & & \\
\cline { 2 - 5 } & $\begin{array}{lll}1(\text { No } \\
\text { disability) } \\
(\boldsymbol{N}=79)\end{array}$ & $\begin{array}{l}2 \text { (mild } \\
\text { disability) } \\
(\boldsymbol{N}=67)\end{array}$ & $\begin{array}{l}3 \text { (moderate } \\
\text { disability) } \\
(\boldsymbol{N}=76)\end{array}$ & $\begin{array}{l}4(\text { severe } \\
\text { disability) } \\
(\boldsymbol{N}=28)\end{array}$ \\
\hline the difficulty level of maintaining a standing position: median (Q1, Q3) & $0(0,0)$ & $1(1,1)$ & $2(2,2)$ & $3(3,3)$ \\
stair climbing time (seconds): mean & 12.43 & 15.29 & 18.01 & 18.23 \\
walking time (seconds): mean & 53.72 & 58.51 & 63.37 & 71.02 \\
\hline
\end{tabular}


Table 3 The comparisons of impairment and participation restriction variables among phenotypes

\begin{tabular}{|c|c|c|c|c|c|}
\hline & $\begin{array}{l}\text { Cluster } 1 \text { (3) } \\
(N=79)\end{array}$ & $\begin{array}{l}\text { Cluster } 2(4) \\
(N=67)\end{array}$ & $\begin{array}{l}\text { Cluster } 3 \text { (2) } \\
(N=76)\end{array}$ & $\begin{array}{l}\text { Cluster } 4(1) \\
(N=28)\end{array}$ & $p$-value $e^{a}$ \\
\hline Pain scale: Mean \pm SD & $3.88 \pm 2.68$ & $4.06 \pm 2.44$ & $4.82 \pm 2.61$ & $5.18 \pm 3.20$ & $0.012^{*}$ \\
\hline FPROM (degree): Mean \pm SD & $131.22 \pm 9.92$ & $127.69 \pm 12.62$ & $123.42 \pm 16.93$ & $118.96 \pm 24.58$ & $0.001^{*}$ \\
\hline EPROM (degree): Mean \pm SD & $3.19 \pm 4.92$ & $5.48 \pm 5.73$ & $5.25 \pm 5.95$ & $5.64 \pm 6.18$ & $0.032^{*}$ \\
\hline Knee flexor muscle power: Median (Q1, Q3) & $4(4,5)$ & $4(4,5)$ & $4(3.25,5)$ & $4(4,5)$ & 0.003 \\
\hline Knee extensor muscle power: Median (Q1, Q3) & $5(4,5)$ & $5(4,5)$ & $4(4,5)$ & $5(4,5)$ & $<0.001$ \\
\hline Acquisition of good and service: Median (Q1, Q3) & $1(0,2)$ & $2(1,2)$ & $2(2,3.75)$ & $3(2,4)$ & $<0.001$ \\
\hline Community life: Median (Q1, Q3) & $1(0,2)$ & $2(1,2)$ & $2(2,3)$ & $3(1,4)$ & $<0.001$ \\
\hline
\end{tabular}

a $p$-values of the Kruskal-Wallis test

Abbreviation: FPROM Flexion passive range of motion, EPROM Extension passive range of motion. *different among clusters at $\mathrm{p}<.05$

worsening, remitting and progressive worsening trajectory [19]. Secondary analysis demonstrated an association between decline of activity and contributing factors of activity limitation including radiographic disease severity, knee pain, obesity and depressive symptom [19].
Other studies have proposed using commonly used functional scores such as WOMAC to identify subgroups of knee OA [6, 30]. However, the WOMAC function subscale could not appropriately predict phenotypes [6, 30]. The study by Egsgaard et al used mixed phenotypic variables including WOMAC subscales,

Table 4 The variance accounted for statistical models of impairment and participation variables for the activty limitation used as cluster variables

\begin{tabular}{|c|c|c|c|c|}
\hline Variables & Impairment and participation variables included in the model & R & $\begin{array}{l}\text { Adjusted } \\
\mathrm{R}^{2}\end{array}$ & $F(p$-value $)$ \\
\hline \multicolumn{5}{|c|}{ Maintaining a standing position } \\
\hline $\begin{array}{l}\text { All subject }(N= \\
250)\end{array}$ & $\begin{array}{l}\text { Extensor, EPROM, Acquisition of good and service, Pain scale, FPROM, Flexor, Community } \\
\text { life }\end{array}$ & .365 & .108 & $5.317(<.001)$ \\
\hline Cluster $1(N=79)$ & $\begin{array}{l}\text { Extensor, Pain scale, Acquisition of good and service, FPROM, EPROM, Flexor, Community } \\
\text { life }\end{array}$ & .602 & .139 & $1.624(.186)$ \\
\hline \multicolumn{5}{|l|}{ Timed walking } \\
\hline All subject $(N=250)$ & $\begin{array}{l}\text { Extensor, EPROM, Acquisition of good and service, Pain scale, FPROM, Flexor, Community } \\
\text { life }\end{array}$ & .540 & .272 & $\begin{array}{l}14.258 \\
(<.001)\end{array}$ \\
\hline Cluster $1(N=79)$ & $\begin{array}{l}\text { Extensor, Pain scale, Acquisition of good and service, FPROM, EPROM, Flexor, Community } \\
\text { life }\end{array}$ & .713 & .337 & $2.957(.027)$ \\
\hline Cluster $2(N=67)$ & $\begin{array}{l}\text { Extensor, EPROM, Acquisition of good and service, Pain scale, FPROM, Community life, } \\
\text { Flexor }\end{array}$ & 619 & .319 & $6.021(<.001)$ \\
\hline Cluster $3(N=76)$ & $\begin{array}{l}\text { Extensor, Acquisition of good and service, Pain scale, Flexor, FPROM, EPROM, Community } \\
\text { life }\end{array}$ & .470 & .144 & $2.874(.011)$ \\
\hline Cluster $4(N=28)$ & $\begin{array}{l}\text { Extensor, FPROM, Pain scale, EPROM, Community life, Flexor, Acquisition of good and } \\
\text { service }\end{array}$ & .550 & .220 & $3.665(.002)$ \\
\hline \multicolumn{5}{|l|}{ Timed stair test } \\
\hline $\begin{array}{l}\text { All subject }(N= \\
250)\end{array}$ & Extensor, EROM, Acquisition of good and service, Pain scale, FPROM, Flexor, Community life & .563 & .297 & $\begin{array}{l}16.057 \\
(<.001)\end{array}$ \\
\hline Cluster $1(N=79)$ & $\begin{array}{l}\text { Extensor, Pain scale, Acquisition of good and service, FPROM, EPROM, Flexor, Community } \\
\text { life }\end{array}$ & .744 & .397 & $3.540(.012)$ \\
\hline Cluster $2(N=67)$ & $\begin{array}{l}\text { Extensor, EPROM, Acquisition of good and service, Pain scale, FPROM, Community life, } \\
\text { Flexor }\end{array}$ & .597 & .290 & $5.366(<.001)$ \\
\hline Cluster $3(N=76)$ & $\begin{array}{l}\text { Extensor, Acquisition of good and service, Pain scale, Flexor, FPROM, EPROM, Community } \\
\text { life }\end{array}$ & .433 & .108 & $2.345(.033)$ \\
\hline Cluster $4(N=28)$ & $\begin{array}{l}\text { Extensor, FPROM, Pain scale, EPROM, Community life, Flexor, Acquisition of good and } \\
\text { service }\end{array}$ & .495 & .155 & $2.730(.016)$ \\
\hline
\end{tabular}


Lequesne index, quality of life, pain catastrophizing, quantitative sensory testing and inflammatory profiles as the clustering variables. Only the pain sensitization profile could identify four distinct phenotypes comprising low sensitivity to pain, early phase sensitization, presence of pain sensitization and presence of pain sensitization and catastrophizing [30]. On the other hand, the secondary comparison of activity limitations among the phenotypes of impairment variables also significantly differed $[31,32]$. This implied a close relationship among the activity limitations and impairments among individuals with knee OA.

In this study, the results of secondary analysis supported that activity limitation variables identified in the cluster analysis could classify participants with knee OA in homogeneous subgroups. The comparisons of impairment and participation restriction variables demonstrated significant differences among phenotypes of all variables. Pain intensity, limited ROM, muscle power and participation restriction levels were worse in subgroups with greater disability accordingly. The impairments related to the activity limitations of each phenotype might be used to develop specific treatment guidelines. Similarly, the related study demonstrated that knee pain and knee flexion ROM also differed among phenotypes based on activity limitations [18].

The major strength of this study was that it identified the common activities which would be disable in persons with knee OA. These activities would be useful in the goal setting process of rehabilitation in patients with different levels of disabilities. However, the study had some limitations. First, the participants included were the patients registered to the primary healthcare settings and diagnosed using the knee OA clinical criteria. No radiographic or other investigations were performed to confirm the structural lesions. Second, due to the crosssectional nature, the cause and effect of the impairments and participation variables on activity limitations could not be identified.

\section{Conclusion}

The cluster analysis confirmed the heterogeneity nature of knee OA. The three activity limitation variables of maintaining a standing position, stair climbing time and walking time could be used to identify homogeneous subgroups of knee OA. Goal setting and treatment planning could be guided by the characteristics of phenotype. However, specific physical therapy management guidelines related to phenotypes are required for further study to identify those completely related factors of these activity limitations.

\section{Abbreviations}

OA: Osteoarthritis; ICF: International classification of functioning, disability and health; ROM: Range of motion; WOMAC: The Western Ontario and
Mcmaster Universities osteoarthritis index; PROM: Passive range of motion; BMl: Body mass index; FPROM: Flexion passive range of motion;

EPROM: Extension passive range of motion

\section{Acknowledgements}

No acknowledgments are applicable.

\section{Authors' contributions}

MV conceptualized and designed the study and drafting/revisions of the manuscript. PN managed the data collected, analyzed and interpreted the data and drafted the manuscript. SS and BA contributed to the conception and design. All authors read and approved the final manuscript.

\section{Funding}

No external funding source was used for this study.

\section{Availability of data and materials}

The datasets used and analyzed during the current study are available from the corresponding author upon reasonable request.

Ethics approval and consent to participate

The protocol for this study was approved by the Mahidol University Central Institutional Review Board (MU-CIRB 2016/073.0308). Each participant also provided written informed consent to this study.

\section{Consent for publication}

Consent for publication is not applicable.

\section{Competing interests}

The authors declare that they have no competing interests.

\section{Author details}

${ }^{1}$ Faculty of Physical Therapy, Mahidol University, Putthamonthon, Nakhon Pathom 73170, Thailand. ${ }^{2}$ Department of Physical Therapy, School of Allied Health Science, Walailak University, Nakhon Si Thammarat, Thailand.

Received: 20 September 2019 Accepted: 2 April 2020

Published online: 13 April 2020

\section{References}

1. Driban JB, Sitler MR, Barbe MF, Balasubramanian E. Is osteoarthritis a heterogeneous disease that can be stratified into subsets? Clin Rheumatol. 2010;29(2):123-31.

2. Fritz JM, George S. The use of a classification approach to identify subgroups of patients with acute low back pain. Interrater reliability and short-term treatment outcomes. Spine (Phila Pa 1976). 2000;25(1):106-14.

3. Creamer P, Lethbridge-Cejku M, Hochberg MC. Where does it hurt? Pain localization in osteoarthritis of the knee. Osteoarthr Cartil. 1998;6(5):318-23.

4. Hinman RS, Crossley KM. Patellofemoral joint osteoarthritis: an important subgroup of knee osteoarthritis. Rheumatology (Oxford). 2007;46(7):1057-62.

5. Deveza LA, Melo L, Yamato TP, Mills K, Ravi V, Hunter DJ. Knee osteoarthritis phenotypes and their relevance for outcomes: a systematic review. Osteoarthr Cartil. 2017;25(12):1926-41.

6. Waarsing $\mathrm{JH}$, Bierma-Zeinstra SM, Weinans $H$. Distinct subtypes of knee osteoarthritis: data from the osteoarthritis initiative. Rheumatology (Oxford). 2015;54(9):1650-8

7. lijima H, Fukutani N, Aoyama T, Fukumoto T, Uritani D, Kaneda E, et al. Clinical phenotype classifications based on static Varus alignment and Varus thrust in Japanese patients with medial knee osteoarthritis. Arthritis Rheumatol. 2015;67(9):2354-62.

8. Merriam-Websterhttps://www.merriam-webster.com/dictionary/phenotype; 2020

9. Cardoso JS, Riley JL 3rd, Glover T, Sibille KT, Bartley EJ, Goodin BR, et al. Experimental pain phenotyping in community-dwelling individuals with knee osteoarthritis. Pain. 2016;157(9):2104-14.

10. Frey-Law LA, Bohr NL, Sluka KA, Herr K, Clark CR, Noiseux NO, et al. Pain sensitivity profiles in patients with advanced knee osteoarthritis. Pain. 2016; 157(9):1988-99.

11. Elbaz A, Mor A, Segal G, Debi R, Shazar N, Herman A. Novel classification of knee osteoarthritis severity based on spatiotemporal gait analysis. Osteoarthr Cartil. 2014;22(3):457-63. 
12. World Health Organization. How to use the ICF: a practical manual for using the international classification of functioning, disability and health (ICF). Geneva, Switzerland; 2013.

13. Xie F, Lo NN, Lee HP, Cieza A, Li SC. Validation of the comprehensive ICF Core set for osteoarthritis $(O A)$ in patients with knee OA: a Singaporean perspective. J Rheumatol. 2007:34(11):2301-7.

14. Alghadir A, Omar MT, Al-Askar AB, Al-Muteri NK. Effect of low-level laser therapy in patients with chronic knee osteoarthritis: a single-blinded randomized clinical study. Lasers Med Sci. 2014;29(2):749-55.

15. Alfredo PP, Bjordal JM, Dreyer SH, Meneses SR, Zaguetti G, Ovanessian V et al. Efficacy of low level laser therapy associated with exercises in knee osteoarthritis: a randomized double-blind study. Clin Rehabil. 2012;26(6): 523-33.

16. Gundog M, Atamaz F, Kanyilmaz S, Kirazli Y, Celepoglu G. Interferential current therapy in patients with knee osteoarthritis: comparison of the effectiveness of different amplitude-modulated frequencies. Am J Phys Med Rehabil. 2012;91(2):107-13.

17. Fukuda TY. Alves da Cunha R, Fukuda VO, Rienzo FA, Cazarini C, Jr., Carvalho Nde a, et al. pulsed shortwave treatment in women with knee osteoarthritis: a multicenter, randomized, placebo-controlled clinical trial. Phys Ther. 2011; 91(7):1009-17.

18. Holla JF, van der Leeden M, Heymans MW, Roorda LD, Bierma-Zeinstra SM, Boers $\mathrm{M}$, et al. Three trajectories of activity limitations in early symptomatic knee osteoarthritis: a 5-year follow-up study. Ann Rheum Dis. 2014;73(7): 1369-75.

19. White DK, Neogi T, Nguyen US, Niu J, Zhang Y. Trajectories of functional decline in knee osteoarthritis: the osteoarthritis initiative. Rheumatology (Oxford). 2016;55(5):801-8.

20. Copsey B, Thompson JY, Vadher K, Ali U, Dutton SJ, Fitzpatrick R, et al. Problems persist in reporting of methods and results for the WOMAC measure in hip and knee osteoarthritis trials. Qual Life Res. 2019;28(2):33543.

21. Woolacott NF, Corbett MS, Rice SJ. The use and reporting of WOMAC in the assessment of the benefit of physical therapies for the pain of osteoarthritis of the knee: findings from a systematic review of clinical trials. Rheumatology (Oxford). 2012;51(8):1440-6.

22. Fisher NM, Gresham GE, Abrams M, Hicks J, Horrigan D, Pendergast DR. Quantitative effects of physical therapy on muscular and functional performance in subjects with osteoarthritis of the knees. Arch Phys Med Rehabil. 1993;74(8):840-7.

23. The Royal Australian College of General Practitioners. Guideline for the management of knee and hip osteoarthritis. 2nd ed. East Melbourne, Vic: RACGP; 2018

24. Salehi-Abari I. 2016 ACR revised criteria for early diagnosis of knee osteoarthritis. Autoimmune Dis Ther Approaches. 2016:3(1):118.

25. Altman R, Asch E, Bloch D, Bole G, Borenstein D, Brandt $K$, et al. Development of criteria for the classification and reporting of osteoarthritis. Classification of osteoarthritis of the knee. Arthritis Rheum. 1986;29(8):103949.

26. Nilmart $P$, Vongsirinavarat $M$, Somprasong S, Apinonkul B. Development of an extensive assessment list for knee osteoarthritis based on the international classification of functioning, disability and health: a Delphi study. Int J Rehabil Res. 2019;42(3):240-8.

27. Hislop H, Avers D, Brown M. Daniels and Worthingham's muscle testing: techniques of manual examination and performance testing. 9th ed. St. Louis: Elsevier; 2014

28. Mooi E, Sarstedt M. A Concise Guide to Market Research: Springer-Verlag Berlin Heidelberg 2011

29. Pirayeh N, Shaterzadeh-Yazdi MJ, Negahban H, Mehravar M, Mostafaee N, Saki-Malehi A. Examining the diagnostic accuracy of static postural stability measures in differentiating among knee osteoarthritis patients with mild and moderate to severe radiographic signs. Gait Posture. 2018;64:1-6.

30. Egsgaard LL, Eskehave TN, Bay-Jensen AC, Hoeck HC, Arendt-Nielsen L. Identifying specific profiles in patients with different degrees of painful knee osteoarthritis based on serological biochemical and mechanistic pain biomarkers: a diagnostic approach based on cluster analysis. Pain. 2015; 156(1):96-107.

31. Knoop J, van der Leeden M, Thorstensson CA, Roorda LD, Lems WF, Knol $\mathrm{DL}$, et al. Identification of phenotypes with different clinical outcomes in knee osteoarthritis: data from the osteoarthritis initiative. Arthritis Care Res (Hoboken). 2011;63(11):1535-42.
32. Kittelson AJ, Stevens-Lapsley JE, Schmiege SJ. Determination of pain phenotypes in knee osteoarthritis: a latent class analysis using data from the osteoarthritis initiative. Arthritis Care Res (Hoboken). 2016;68(5):612-20.

\section{Publisher's Note}

Springer Nature remains neutral with regard to jurisdictional claims in published maps and institutional affiliations.
Ready to submit your research? Choose BMC and benefit from:

- fast, convenient online submission

- thorough peer review by experienced researchers in your field

- rapid publication on acceptance

- support for research data, including large and complex data types

- gold Open Access which fosters wider collaboration and increased citations

- maximum visibility for your research: over $100 \mathrm{M}$ website views per year

At BMC, research is always in progress.

Learn more biomedcentral.com/submissions 